\title{
CONCEPTUAL DESIGN OF MARS SUB-SURFACE HABITAT FOR SUSTAINING THERMAL STABILITY
}

\author{
Malaya Kumar Biswal M${ }^{\mathbf{1}}$, David Gómez Fernández ${ }^{2}$, Noor Basanta Das ${ }^{3}$, Ramesh Naidu Annavarapu ${ }^{4}$ \\ ${ }^{1,4}$ Graduate Researcher, ${ }^{4}$ Associate Professor, Department of Physics, Pondicherry University, Puducherry, India. \\ ${ }^{2}$ M.Sc. Civil Engineer (Ingeniero de Caminos, Canales y Puertos), Spanish Institution of Civil Engineers, Spain. \\ Email: malaykumar1997@gmail.com; dgomezfr@gmail.com.
}

Introduction: The surface of Mars is seasoned with hostile climate, recurrent dusty sand storms, exposure to galactic cosmic radiation, and temperature variance that persuaded a challenging environment for performing science mission operations. A human mission to Mars requires extended presence for approximately 180-270 days since regular interplanetary transit is limited due to its far distance and technology limitation. So it is significant to have a confined habitat that can ensure crew protection as well as sustainable presence thereby affording necessities. In addition to this, the surface temperature of Mars varies from $\left(-125^{\circ} \mathrm{C}\right.$ to $\left.20^{\circ} \mathrm{C}\right)$ that pose a greater challenge for life forms and crews to sustain thermal stability. Improper temperature balance may lead the crew to experience the effect of hypothermia and frost formation. Hence considering the entire challenges of human survival of Mars, we propose a novel "Mars Sub-Surface Habitat" capable of stabilizing habitat's internal temperature during nighttime. Further, the habitat is environment tolerant to keep the astronauts secure from every critical condition. Its thermal stability is enhanced by the thickened wall structure sealed with either in-situ thermal insulating material or synthetic insulators. Apart from its wall design, its potentiality to isolate itself from the surface environment at night triggers additional temperature stability. Keeping eye on the forthcoming human expedition mission and the strategy for human settlement, we hope this kind of habitat may afford a favourable compact home for a safe and sustainable mission. The habitat is proposed base on the concept that the subsurface of Mars seems to be a perfect platform for future Martians.

Design Overview: The proposed habitat is ovoid to retain adequate pressure within it. Then the habitat is integrated into a supporting base with seismic bearings to compensate the impact of seismic effect imposed over the structure by the blowing dust storms and the seismic effect of Mars quakes. Then the supporting base is fixed over the telescopic based retractable legs (hydraulic made) shown in Figure 1. In between the telescopic arms, we have braced metallic cables to avoid buckling or deformation of arms due to slenderness of the hydraulic system. In addition to this, we have provided habitat supporting arm to withhold the habitat during day-time (when the habitat is on the surface) to avoid continuous pressure over the hydraulic system that can cause breakage of oil seals. Finally, the complete structure is supposed to assemble beneath the surface enveloped by Martian regolith filled dome system shown in Figure 2. The dome structure is to improve the extent of isolation of the habitat during night-time and for restraining dust deposition inside the assembly. Because the dust deposition at the interior part of the hydraulic setup may cost periodic maintenance. Therefore, the dome protects the habitat from dust deposition and its regolith filled layer ensures additional shielding from exposure to surface radiation.

Working: The habitat goes down and submerges itself beneath the surface at night for isolation from the surface environment and comes up into the surface during day-time to avail solar resources. Its reciprocating motion is powered by a hydraulic system and can be controlled via either automated or manual method. But the automated operation is fortified by a day-night sensor.

\section{Habitat Features}

- Ensures isolation against the hostile environment

- Effective against recurrent sand storms

- Effective against surface radiation and seismic effect of Mars quakes.

- Enhances thermal stability of habitat

- Afford a favourable environment for the growth of life forms

- Effective for retaining optimal pressure and atmosphere.

Conclusion: Considering significant challenges for human presence beyond the terrestrial planet and on Mars, we have proposed a novel design of habitat for sustaining thermal stability which is very essential to keep the crew warm against a hostile environment and for effective functioning for robust computers and pieces of machinery. Further, this kind of sub-surface habitat can be extended to deploy on Moon and any other planetary surface for sustainable human settlement. 


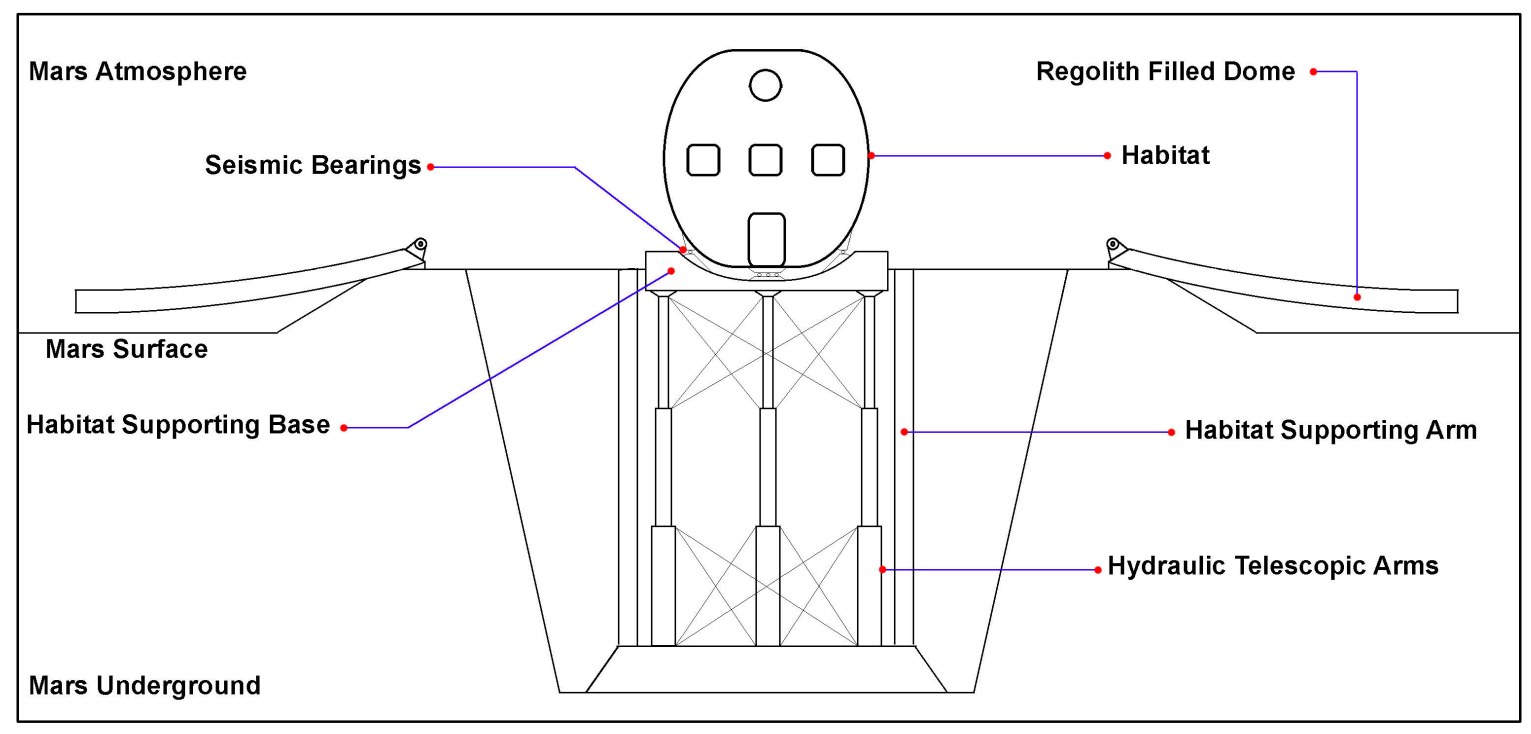

Figure 1 Mars Sub-Surface Habitat at Daytime

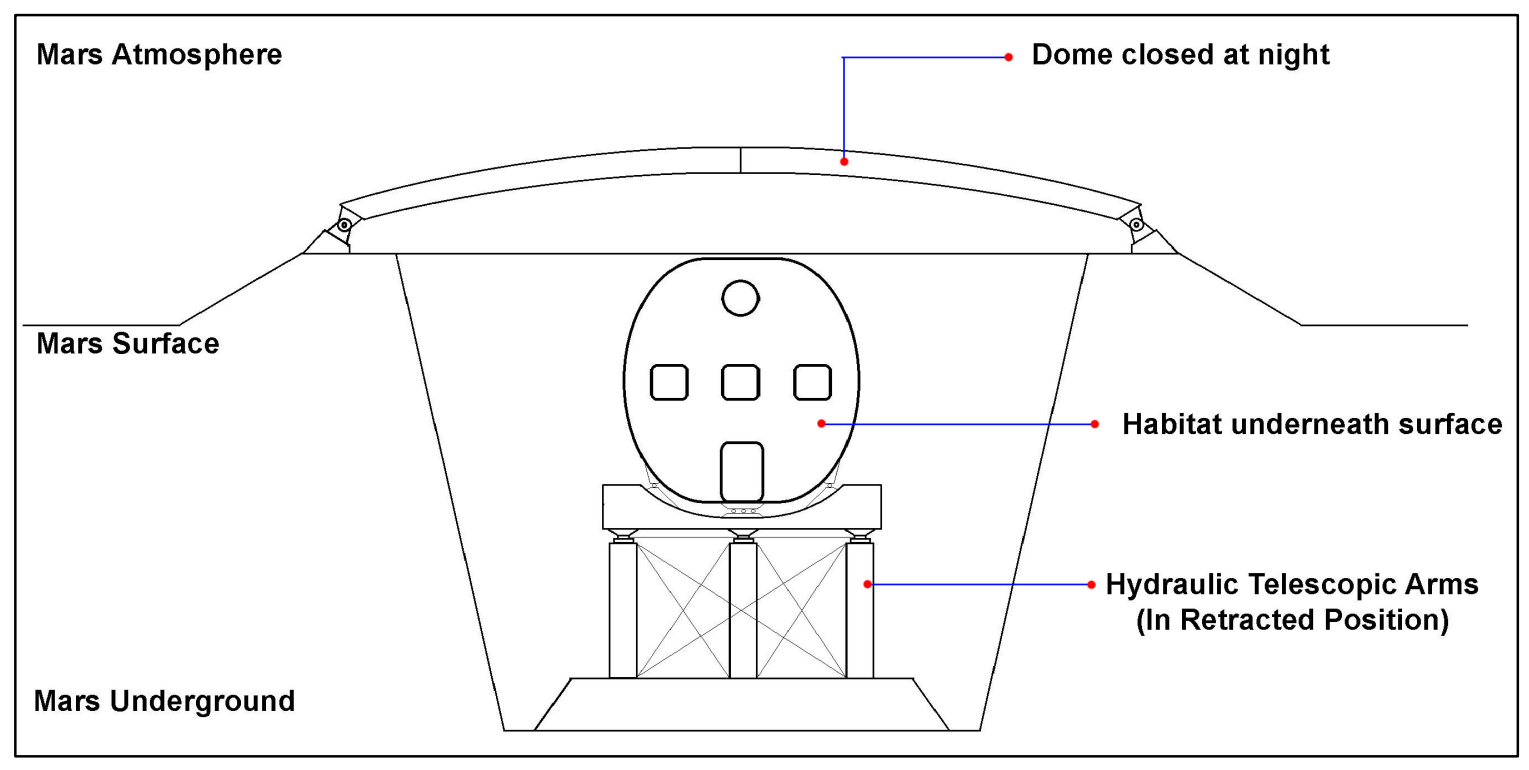

Figure 2 Mars Sub-Surface Habitat at Nighttime

\section{References}

[1] Shubber, Kadhim. "Concept for underground Mars habitat marks dawn of Martian mole-people (Wired UK)". Wired.co.uk. Retrieved 2021-01-06.

[2] Fernández-Remolar, D. C., Prieto-Ballesteros, O., Rodríguez, N., Gómez, F., Amils, R., Gómez-Elvira, J., \& Stoker, C. R. (2008). Underground habitats in the Río Tinto basin: a model for subsurface life habitats on Mars. Astrobiology, 8(5), 1023-1047.

[3] Biswal M, M. K., \& Annavarapu, R. N. (2021). Human Mars Exploration and Expedition Challenges. In AIAA Scitech 2021 Forum (p. 0628).
[4] Boston, P. J., \& Strong, J. D. (2005). Lunar and Martian Sub-surface Habitat Structure Technology Development and Application.

[5] Ravi, R. K. Making Mars Our Next Abode. 